\title{
Commentary: From 2-dimensional to 3-dimensional- Tailor-made transcatheter aortic valve replacement to minimize complications
}

\author{
Hiroto Kitahara, MD, J. James Edelman, MBBS(Hons), PhD, and Vinod H. Thourani, MD
}

\footnotetext{
From the Department of Cardiac Surgery, MedStar Heart and Vascular Institute, Georgetown University, Washington, DC.

Disclosures: Dr Thourani is and advisor and conducts research for Edwards Lifesciences. All other authors have nothing to disclose with regard to commercial support.

Received for publication May 1, 2019; accepted for publication May 3, 2019; available ahead of print June 14, 2019.

Address for reprints: Vinod H. Thourani, MD, Department of Cardiac Surgery, 110 Irving St, Suite 6D15G, Washington, DC 20010 (E-mail: vinod.h.thourani@medstar.net).

J Thorac Cardiovasc Surg 2020;159:842-3

$0022-5223 / \$ 36.00$

Copyright (c) 2019 by The American Association for Thoracic Surgery

https://doi.org/10.1016/j.jtcvs.2019.05.007
}

Coronary obstruction is a rare but catastrophic complication after transcatheter aortic valve replacement (TAVR). ${ }^{1}$ It is most often caused by over-displacement of the aortic valve leaflet, causing obstruction of the coronary ostium. Precise simulation of the interaction between a patient's anatomy and the TAVR valve is the goal to prevent this complication. In this issue of the Journal, Heitkemper and colleagues $^{2}$ report a retrospective simulation study in which they used patient-specific 3-dimensional (3D) model to predict post-TAVR coronary obstruction. From a population of 600 TAVR cases from their institution, they created computational 3D aortic root model of 28 patients who were flagged as being at high risk for coronary obstruction (defined as either coronary ostium height $<14 \mathrm{~mm}$ or sinus of Valsalva width $<30 \mathrm{~mm}$ ). Five of these 28 patients had unsuccessful TAVR. In the 3D model analysis, a specific parameter, distance from cusp to coronary ostium indexed with the coronary diameter, was significantly different between the models of the patients who underwent successful TAVR and the models of those who did not. A cutoff value of for the distance from cusp to coronary ostium indexed with the coronary diameter of 0.7 was a better predictive parameter, with $100 \%$ sensitivity and $95.7 \%$ specificity, than either coronary height or sinus of Valsalva width.

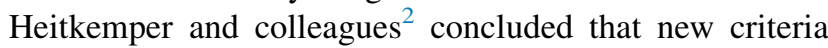
including the parameter obtained from patient-specific 3D aortic root modeling would possibly increase the number of patients undergoing TAVR safely.

Predicting the risk of coronary obstruction can be challenging and has been met with significant contention. In the multicenter registry from which predictors of coronary obstruction (coronary height $<12 \mathrm{~mm}$, sinuses of Valsalva $<30 \mathrm{~mm}$ ) are derived, $21 \%$ of patients with obstruction had height greater than $12 \mathrm{~mm}$, and $35 \%$ had sinuses of Valsalva greater than $30 \mathrm{~mm} .{ }^{1}$ Others (eg, Spina and associates $^{3}$ and Okuyama and coworkers ${ }^{4}$ ) have suggested a investigation.

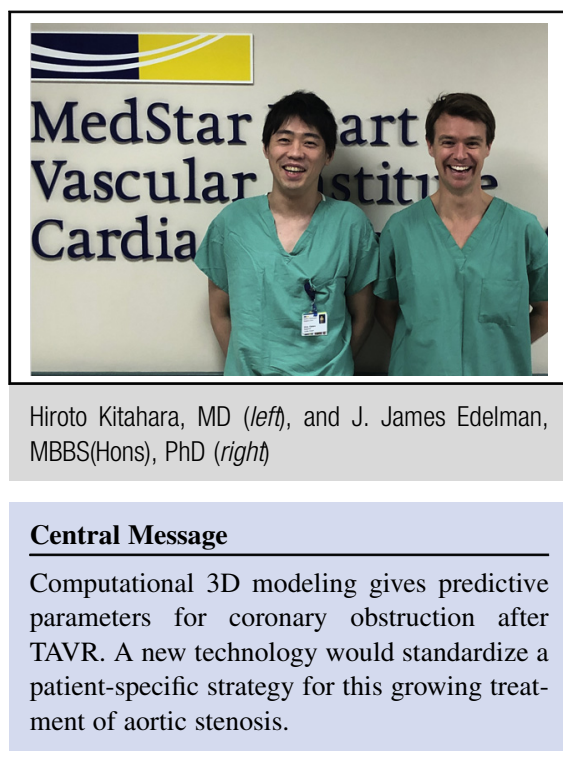

See Article page 829.

ratio of leaflet length to curved coronary sinus height as another potential predictor. For valve-in-valve TAVR, where the risk of obstruction is approximately 4 times that of native valve TAVR, a valve to coronary ostium distance less than $4 \mathrm{~mm}$ predicts obstruction. ${ }^{5}$ Multidetector computed tomography can be used to create a virtual cylinder of diameter equal to that of the planned TAVR that extends distally from the basal ring of the surgical valve; the distance from the cylinder to the coronary ostium is the valve to coronary ostium distance. ${ }^{6}$ By using $3 \mathrm{D}$ computer modeling, Heitkemper and colleagues ${ }^{2}$ appear to have created a similar concept for use in the native valve. Their addition of the coronary ostial diameter to yield a fractional obstruction measure is interesting and requires further

Others have used computational 3D modeling to predict paravalvular regurgitation, ${ }^{7}$ predict conduction abnormalities, ${ }^{8}$ and manage challenging anatomic scenarios, such as a high-profile prosthetic valve in the mitral position. ${ }^{9} \mathrm{~A}$ $3 \mathrm{D}$ printing technology has taken this computational simulation one step further and enabled the testing of actual physical interactions between a TAVR valve and patientspecific aortic root in vitro. ${ }^{10}$ The benefit of this technology is the ability to obtain a direct visualization of the anatomy 
as in open surgery and also simulate the fluid dynamics with computational modeling. Although these technologies are still in development, they will bring patient-specific treatment-tailor-made TAVR - in the near future. We congratulate Heitkemper and colleagues ${ }^{2}$ for identifying new risk predictors for this important complication after TAVR by utilizing computational modeling. Recently, Khan and colleagues $^{11}$ reported successful TAVR even in extremely high-risk patients (median coronary height of $6.8 \mathrm{~mm}$ and sinus of Valsalva width of $24.3 \mathrm{~mm}$ ) by using a unique pre-TAVR intentional laceration technique to prevent coronary obstruction. These novel procedures and technologic developments allow more precise patient selection and safe placement of TAVR valves, even in high-risk patients.

\section{References}

1. Ribeiro HB, Webb JG, Makkar RR, Cohen MG, Kapadia SR, Kodali S, et al. Predictive factors, management, and clinical outcomes of coronary obstruction following transcatheter aortic valve implantation: insights from a large multicenter registry. J Am Coll Cardiol. 2013;62:1552-62.

2. Heitkemper M, Hatoum H, Azimian A, Yeats B, Dollery J, Whitson B, et al. Modeling risk of coronary obstruction during transcatheter aortic valve replacement. J Thorac Cardiovasc Surg. 2020;159:829-38.e3.

3. Spina R, Khalique O, George I, Nazif T. Acute left main stem coronary occlusion following transcatheter aortic valve replacement in a patient without recognized coronary obstruction risk factors: a case report. Eur Heart J Case Rep. 2018;2: 1597.
4. Okuyama K, Jilaihawi H, Makkar RR. Leaflet length and left main coronary artery occlusion following transcatheter aortic valve replacement. Cathet Cardiovasc Interv. 2013;82:E754-9.

5. Ribeiro HB, Rodés-Cabau J, Blanke P, Leipsic J, Kwan Park J, Bapat V, et al. Incidence, predictors, and clinical outcomes of coronary obstruction following transcatheter aortic valve replacement for degenerative bioprosthetic surgical valves: insights from the VIVID registry. Eur Heart J. 2018;39:687-95.

6. Blanke P, Soon J, Dvir D, Park JK, Naoum C, Kueh SH, et al. Computed tomography assessment for transcatheter aortic valve in valve implantation: the Vancouver approach to predict anatomical risk for coronary obstruction and other considerations. J Cardiovasc Compu Tomogr. 2016;10:491-9.

7. de Jaegere P, De Santis G, Rodriguez-Olivares R, Bosmans J, Bruining N, Dezutter T, et al. Patient-specific computer modeling to predict aortic regurgitation after transcatheter aortic valve replacement. JACC Cardiovasc Interv. 2016; 9:508-12.

8. Rocatello G, El Faquir N, De Santis G, Iannaccone F, Bosmans J, De Backer O, et al. Patient-specific computer simulation to elucidate the role of contact pressure in the development of new conduction abnormalities after catheter-based implantation of a self-expanding aortic valve. Circ Cardiovasc Interv. 2018;11: e005344.

9. Obaid DR, Smith D, Gilbert M, Ashraf S, Chase A. Computer simulated "virtual TAVR" to guide TAVR in the presence of a previous Starr-Edwards mitral prosthesis. J Cardiovasc Comput Tomogr. 2019;13:38-40.

10. Qian Z, Wang K, Liu S, Zhou X, Rajagopal V, Meduri C, et al. Quantitative prediction of paravalvular leak in transcatheter aortic valve replacement based on tissue-mimicking 3D printing. JACC Cardiovasc Imaging. 2017 10:719-31.

11. Khan JM, Dvir D, Greenbaum AB, Babaliaros VC, Rogers T, Aldea G, et al. Transcatheter laceration of aortic leaflets to prevent coronary obstruction during transcatheter aortic valve replacement: concept to first-in-human. JACC Cardiovasc Interv. 2018;11:677-89. 